\title{
Elastostatic effects around a magma reservoir and pathway due to historic earthquakes: a case study of Mt. Fuji, Japan
}

\author{
Masaki Hosono, Yuta Mitsui* ${ }^{*}$, Hidemi Ishibashi and Jun Kataoka
}

\begin{abstract}
We discuss elastostatic effects on Mt. Fuji, the tallest volcano in Japan, due to historic earthquakes in Japan. The 1707 Hoei eruption, which was the most explosive historic eruption of Mt. Fuji, occurred 49 days after the Hoei earthquake (Mw 8.7) along the Nankai Trough. It was previously suggested that the Hoei earthquake induced compression of a basaltic magma reservoir and unclamping of a dike-intruded region at depth, possibly triggering magma mixing and the subsequent Plinian eruption. Here, we show that the 1707 Hoei earthquake was a special case of induced volumetric strain and normal stress changes around the magma reservoir and pathway of Mt. Fuji. The 2011 Tohoku earthquake (Mw 9), along the Japan Trench, dilated the magma reservoir. It has been proposed that dilation of a magma reservoir drives the ascent of gas bubbles with magma and further depressurization, leading to a volcanic eruption. In fact, seismicity notably increased around Mt. Fuji during the first month after the 2011 Tohoku earthquake, even when we statistically exclude aftershocks, but the small amount of strain change $(<1 \mu$ strain) may have limited the ascent of magma. For many historic earthquakes, the magma reservoir was compressed and the magma pathway was wholly clamped. This type of interaction has little potential to mechanically trigger the deformation of a volcano. Thus, Mt. Fuji may be less susceptible to elastostatic effects because of its location relative to the sources of large tectonic earthquakes. As an exception, a possible local earthquake in the Fujikawa-kako fault zone could induce a large amount of magma reservoir dilation beneath the southern flank of Mt. Fuji.
\end{abstract}

Keywords: Volcano-earthquake interactions, Elastostatic deformation, Epidemic-type aftershock sequence model, Boundary-element method simulation, Dike, Magma pathway, Magma reservoir, Mt. Fuji, 2011 Tohoku earthquake, 1707 Hoei earthquake

\section{Introduction}

Volcano-earthquake interactions have been discussed mainly from a statistical perspective. A previous study (Linde and Sacks 1998) found that the frequency of volcanic eruptions tended to increase within 1 or 2 days after nearby large earthquakes. Another study (Lemarchand and Grasso 2007) showed that volcanic eruptions also increased before earthquakes and proposed a conceptual model of regional tectonic coupling between volcanoes and earthquakes. Such reports are scientifically interesting; thus, we approach this issue in terms of mechanical effects. In particular,

\footnotetext{
* Correspondence: mit@shizuoka.ac.jp

Department of Geosciences, Shizuoka University, Suruga-ku, Shizuoka 422-8529, Japan
}

we focus on the tallest volcano in Japan, Mt. Fuji $(3776 \mathrm{~m})$.

A stratified basaltic volcano, Mt. Fuji has been active for over 10,000 years (Miyaji 1988). The last eruption from the summit was the Yufune-2 eruption, around 2200 years ago (Suzuki and Fujii 2010), but lateral eruptions are recorded in many historic documents and eruptive deposits (Koyama 1998). At least 10 lateral eruption events have occurred since the eight century. The last reliable eruption report was the 1707 Hoei eruption, which was extremely explosive and ejected andesitic or dacitic material prior to massive volumes of basaltic material (Tsuya 1955). Mt. Fuji is located around the junction of the Eurasian Plate (Amurian microplate), the North American Plate (Okhotsk microplate), and the Philippine Sea Plate (Izu 
microplate), as shown in Fig. 1. Radial dikes beneath Mt. Fuji mainly develop in a northwest-southeast alignment, which may derive from collision between the Izu Peninsula on the Philippine Sea Plate and the North American Plate (Nakamura 1977; Ida 2009).

One of the largest eruptions of Mt. Fuji, the VEI 5 Hoei eruption, occurred in 1707 as a lateral eruption in a region of northwest-southeast striking dikes. At 49 days before the eruption, a large interplate earthquake ( $\mathrm{Mw}$ 8.7) occurred at the interface between the Eurasian Plate and the Philippine Sea Plate. A previous study (Nakamura 1975) discussed this issue and proposed that the large earthquake reduced the minimum principal stress in the region, leading to the lateral eruption.

On the basis of this example, a recent study (Chesley et al. 2012) calculated elastostatic stress effects caused by the 1707 Hoei earthquake and the 1703 Genroku Kanto earthquake (Mw 8.2) beneath Mt. Fuji. They translated the dike-intruded region along the northwest-southeast direction into a simplified vertical plane (hereinafter called the "dike plane", as the main magma pathway), as shown in Fig. 2, and estimated normal stress changes perpendicular to this plane. Their results suggest that both earthquakes clamped the dike plane at shallow depths, but the 1707 Hoei earthquake also unclamped the deeper dike plane, above a basaltic

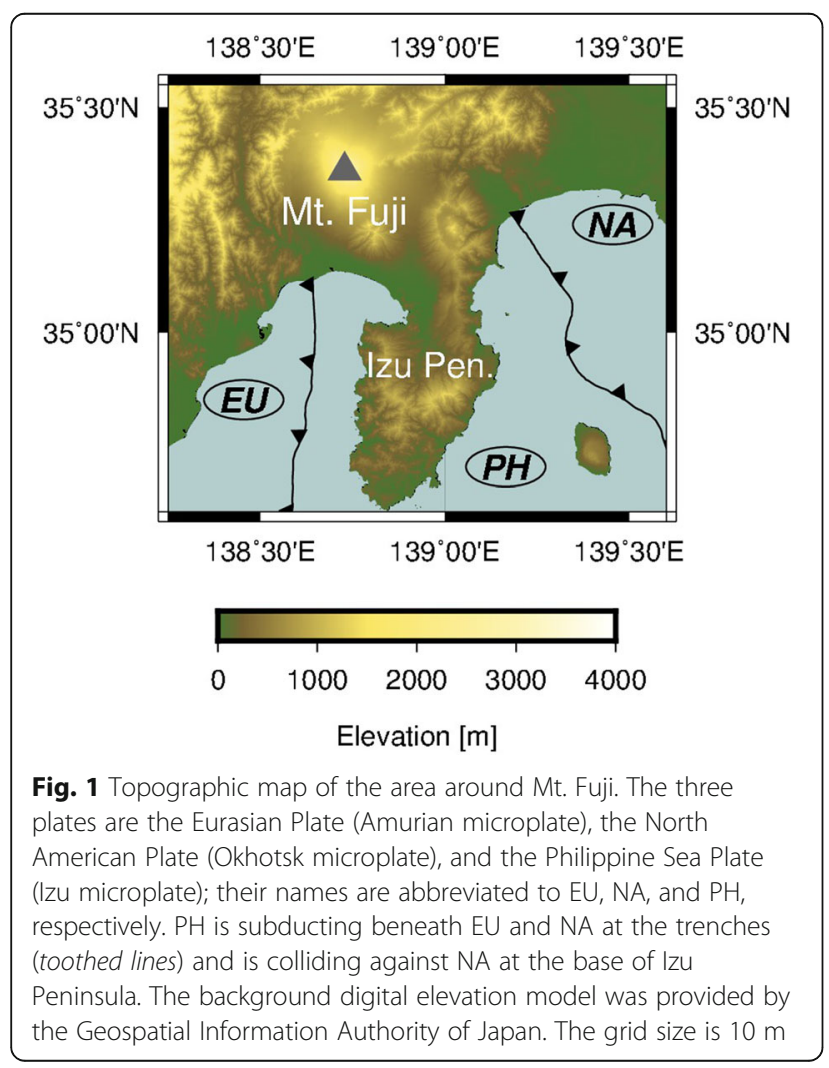

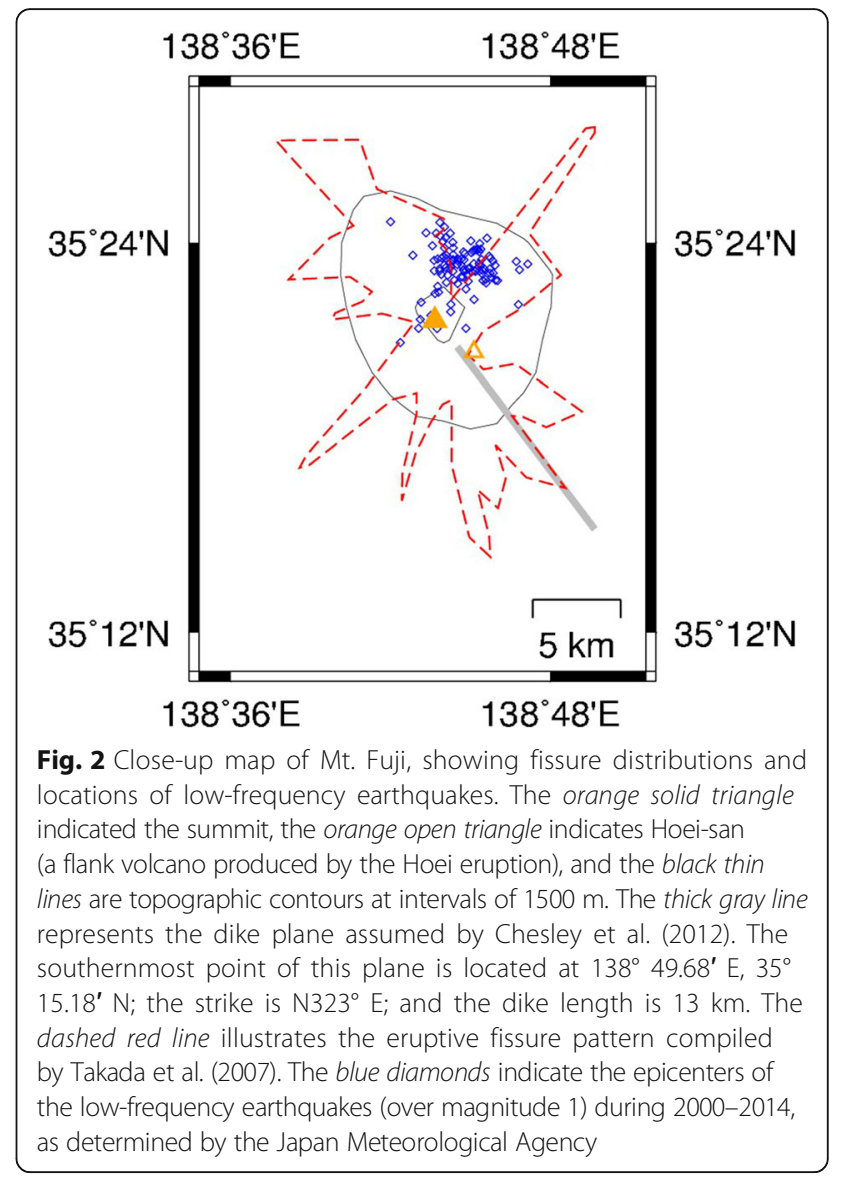

magma reservoir ( 20 km depth). The 1707 Hoei earthquake could have triggered the Plinian Hoei eruption of Mt. Fuji due to the mixing of basaltic and more silicic magmas via induced ascent of basaltic magma (Eichelberger 1980). Although elastodynamic stress changes by seismic waves would also influence the magma reservoir state (Manga and Brodsky 2006), the elastostatic model sufficiently explains the features of the 1707 Hoei eruption (Chesley et al. 2012). Since the amplitude and frequency of seismic wave radiation depend strongly on the heterogeneities of the source fault(s), it is difficult to discuss the effects of dynamic stress changes due to historic earthquakes.

Here, we note that the main dike region of Mt. Fuji was not the only path of ascending magma near the surface. For example, a geological study (Takada et al. 2007) investigated eruptive fissure patterns at Mt. Fuji and showed a spatially asymmetric distribution (Fig. 2). Eruptive fissures are concentrated mainly in the direction of the dike plane (aligned northwest-southeast) but are also distributed in other directions. This observation implies that local stress heterogeneities other than the collision-induced regional stress field (Ukawa 1991) can 
play an important role in constraining the locations of eruptive fissures. Araragi et al. (2015) investigated the anisotropic structure beneath Mt. Fuji by shear wave splitting and found a radial pattern of fast polarization directions toward the summit at depths shallower than $4 \mathrm{~km}$, which reflects gravitational stress effects due to mountain loads. In addition, (magmatic) deep lowfrequency earthquakes have occurred on the northeast side of the volcanic edifice (Nakamichi et al. 2004), seemingly located off the dike plane. An increase in seismicity after the 2011 Tohoku earthquake (Enescu et al. 2012) occurred along a different direction from that of the dike plane.

In this study, we evaluate the elastostatic effects beneath Mt. Fuji due to large (Mw 8 or Mw 9 class) earthquakes in Japan. First, we calculate the volumetric strain changes around the magma reservoir and the dike plane, and the normal stress changes perpendicular to the dike plane, using several scenarios modeled using historic earthquakes near Mt. Fuji, to compare with two existing hypotheses for eruption-triggering processes due to earthquakes. Next, we calculate the elastostatic effects for another direction (nearly north-south) along a weak zone as a representative example of a possible magma ascent path and discuss the response of the volcano system in terms of compression/dilation of the magma reservoir and clamping/unclamping of the magma pathway.

\section{Methods/Experimental}

Elastostatic modeling of earthquake deformation

We evaluate strain and stress changes beneath Mt. Fuji from fault dislocations of large ( $\mathrm{Mw} 8$ or Mw 9 class) earthquakes. To calculate the elastostatic effects, we take a classical boundary-element approach. A strain change tensor $\Delta \varepsilon$ at an observation point due to an earthquake is given by

$$
\Delta \boldsymbol{\varepsilon}=\sum_{\text {fault }} \boldsymbol{G} \boldsymbol{u}
$$

where $\boldsymbol{G}$ is a Green's function tensor that includes the effects of fault location, size, and strike/dip angle and the Poisson's ratio of the elastic material, and $\boldsymbol{u}$ is a dislocation vector at each fault. We use the Green's function in a homogeneous elastic half-space for a rectangular fault (Okada 1992) with an assumed Poisson's ratio of 0.25 .

We consider large earthquakes that occurred near Mt. Fuji using simplified fault models as scenario earthquakes that could affect Mt. Fuji. Figure 3 presents five such scenario earthquakes. The first is the 1707 Hoei earthquake (Mw 8.7) along the Nankai Trough (Fig. 3a), and the second is the 1703 Genroku Kanto earthquake (Mw 8.2) along the Sagami Trough (Fig. 3b). Both were previously modeled by Chesley et al. (2012). The third is the 2011 Tohoku earthquake along the Japan Trench

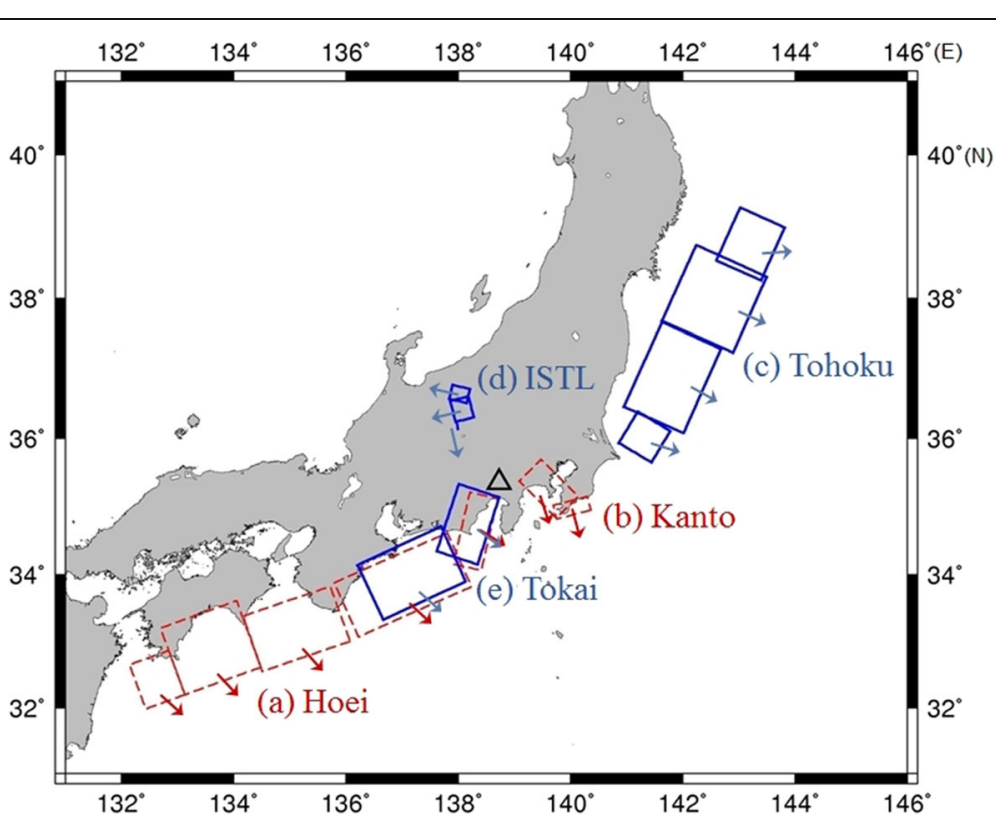

Fig. 3 Earthquake scenarios around Japan. The rectangles show five earthquake scenarios that could affect Mt. Fuji (black triangle). Two of them (red dashed rectangles) are the same as those of Chesley et al. (2012), whereas the others (blue rectangles) are not. The corresponding fault parameters are listed in Table 1. The vectors on the faults represent the movement directions of their hanging walls. a The 1707 Hoei earthquake within the Nankai Trough, with five subfaults. b The 1703 Genroku Kanto earthquake within the Sagami Trough, with two subfaults. c The 2011 Tohoku earthquake within the Japan Trench, with four subfaults. $d$ The ISTL earthquake, with three subfaults. e The 1854 Ansei Tokai earthquake, with two subfaults 
(Fig. 3c). In contrast to the three interplate thrust earthquakes, the fourth (Fig. 3d) is the 762 (or 841) inland earthquake, roughly as large as $\mathrm{Mw} 8$, along the Itoigawa-Shizuoka Tectonic Line, which may have repeated historically (Okumura 2001; Kondo et al. 2008); herein, we call this the ISTL earthquake. The fifth (Fig. 3e) is the 1854 Ansei Tokai earthquake (Mw 8.2), which was once believed to have partly ruptured the source fault of the 1707 Hoei earthquake (Ando 1975; Ishibashi 2004) but was recently reevaluated as a unique type of large earthquake, distinct from the Hoei earthquake (Seno 2012). Table 1 shows the fault parameters for the scenario earthquakes.

\section{Results and discussion}

\section{Elastostatic modeling of earthquake deformation}

We first calculate the spatial distribution of the volumetric strain changes (the sum of the normal components of the tensor). The volumetric strain change around the magma reservoir may relate to an increasing magma overpressure effect (Walter and Amelung 2007) as a source of eruption. Although the spatial distribution of the magma reservoir beneath Mt. Fuji remains unclear, a seismic tomography study (Nakamichi et al. 2007) revealed a high-Vp/Vs anomaly around $15-25 \mathrm{~km}$ depth that is interpreted as a zone of basaltic partial melting. Another study (Kinoshita et al. 2015) used receiver function analysis to show a seismic velocity contrast at $20-30 \mathrm{~km}$ depth, which can be related to the bottom of the magma chamber. In addition, over $90 \%$ of (magmatic) low-frequency earthquakes in Fig. 2 occurred in a depth range of $10-20 \mathrm{~km}$. Thus, we focus on the strain changes at a depth of $20 \mathrm{~km}$, treating this as a typical value for the depth of a basaltic magma reservoir beneath Mt Fuji.

Figure 4 shows a map view of volumetric strain changes due to each earthquake scenario. Although we do not know the precise geometry of the magma reservoir, it should be around or within the area below the eruptive fissures. The calculated results show that three earthquakes, (a), (b), and (e), cause compression around the magma reservoir and the other earthquakes, (c) and (d), cause dilation. The compressions are one order of magnitude larger than the dilations. Figure 5 further shows the volumetric strain changes in a vertical cross-section along an extended dike plane (the main pathway of Mt. Fuji's magma), where we extend the dike plane in Chesley et al. (2012) from $13 \mathrm{~km}$ length to $30 \mathrm{~km}$.

Next, we calculate the normal stress changes for the extended dike plane from the strain changes, assuming a rigidity of $30 \mathrm{GPa}$. The normal stress change perpendicular to the extended dike plane works as an opening force for a magma pathway in terms of fracture mechanics (Pollard and Segall 1987); Bonali et al. (2013) emphasized the importance of this effect. Figure 6 illustrates the normal stress changes due to the five earthquakes. In many cases, the extended dike plane is wholly clamped. Only in the case of (c), the 2011 Tohoku

Table 1 Fault parameters used in this study. The parameters for (a) and (b) follow Chesley et al. (2012). Those for (c) are from a geodetic study (Nishimura et al. 2011) including the largest aftershock. We set the parameters for (d) on the basis of underground and surface fault geometry (Sato et al. 2004; Panayotopoulos et al. 2014). The parameters for (e) are from Ishibashi (1977)

\begin{tabular}{|c|c|c|c|c|c|c|c|c|c|}
\hline Name & Long..$^{\mathrm{a}}\left[{ }^{\circ} \mathrm{E}\right]$ & Lati. ${ }^{\mathrm{a}}\left[{ }^{\circ} \mathrm{N}\right]$ & $\operatorname{Depth}^{\mathrm{a}}[\mathrm{km}]$ & Length [km] & Width [km] & Strike $\left[^{\circ}\right]$ & Dip [] & Rake $\left[{ }^{\circ}\right]$ & Slip [m] \\
\hline (a)-1 & 138.706 & 35.120 & 6.4 & 120 & 50 & 193 & 20 & 71 & 5.6 \\
\hline (a)-2 & 138.235 & 33.823 & 4.1 & 205 & 100 & 246 & 10 & 113 & 7.0 \\
\hline (a) -3 & 136.074 & 33.006 & 7.8 & 155 & 100 & 251 & 12 & 113 & 5.6 \\
\hline (a) -4 & 134.481 & 32.614 & 10.1 & 135 & 120 & 250 & 8 & 113 & 9.2 \\
\hline (a) -5 & 133.130 & 32.200 & 10.0 & 70 & 80 & 250 & 8 & 118 & 9.2 \\
\hline (b) -1 & 139.748 & 34.836 & 2.0 & 85 & 50 & 315 & 30 & 153 & 6.7 \\
\hline (b) -2 & 140.360 & 34.954 & 2.0 & 57 & 23 & 255 & 20 & 90 & 12.0 \\
\hline (c) -1 & 143.815 & 38.994 & 8.0 & 90 & 76 & 204 & 16 & 119 & 40.90 \\
\hline (c) -2 & 143.494 & 38.303 & 7.9 & 130 & 122 & 204 & 17 & 90 & 17.40 \\
\hline (c) -3 & 142.680 & 37.285 & 7.9 & 147 & 104 & 204 & 16 & 85 & 4.70 \\
\hline (c) -4 & 141.777 & 36.106 & 8.7 & 59 & 61 & 211 & 26 & 104 & 3.76 \\
\hline$(d)-1$ & 137.840 & 36.570 & 0.0 & 23.0 & 30 & 13 & 14 & 90 & 10.0 \\
\hline (d) -2 & 137.950 & 36.240 & 0.0 & 34.6 & 30 & 346 & 14 & 90 & 10.0 \\
\hline (d) -3 & 138.074 & 36.125 & 0.0 & 10.8 & 15 & 347 & 90 & 0 & 9.0 \\
\hline$(e)-1$ & 138.730 & 35.140 & 2.0 & 115 & 70 & 198 & 34 & 71 & 4.0 \\
\hline (e)-2 & 138.130 & 33.900 & 3.0 & 150 & 100 & 245 & 24 & 113 & 4.0 \\
\hline
\end{tabular}

a Locations at the southern corner of an upper edge of a rectangular fault when the strike is $0^{\circ}$ 

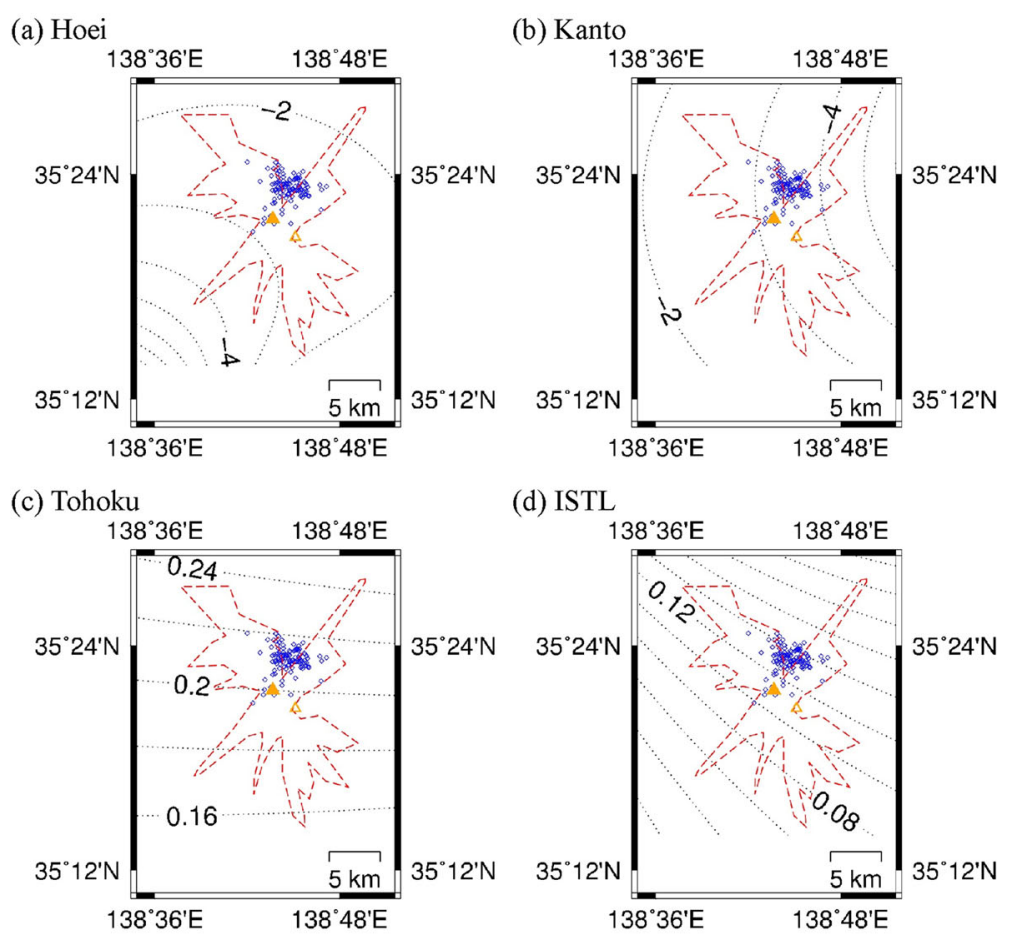

(d) ISTL

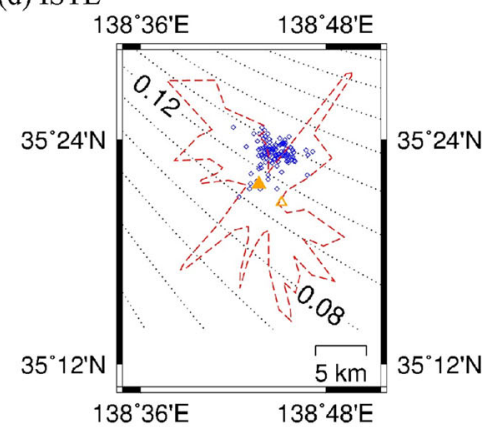

(e) Tokai

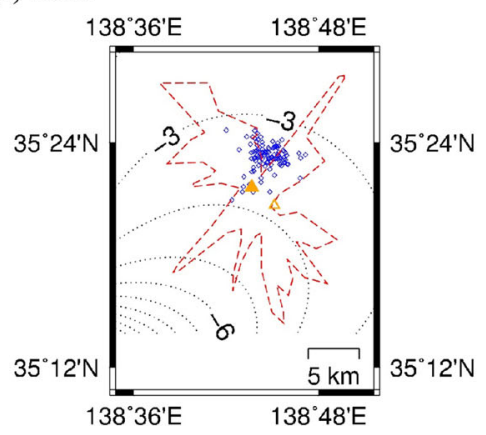

Fig. 4 a-e Map view of volumetric strain changes due to earthquakes. The dotted lines represent isograms of volumetric strain changes in each of the five earthquake scenarios (Fig. 3) at a depth of $20 \mathrm{~km}$ beneath Mt. Fuji. The unit is $1 \mu$ strain. Positive values indicate dilation, and negative values indicate compression. The orange solid triangle, orange open triangle, red broken line, and blue squares have the same meanings as in Fig. 2

earthquake, is the extended dike plane totally unclamped. As reported by Chesley et al. (2012), case (a) shows that the 1707 Hoei earthquake caused unclamping in a deep region of the dike plane, which could have triggered the Hoei eruption.

\section{Two hypotheses that explain eruption triggering by elastostatic deformation}

We estimated two kinds of elastostatic effects: volumetric strain changes around the basaltic magma reservoir and normal stress changes perpendicular to the extended dike plane (the main pathway of Mt. Fujis magma). Because we do not consider material contrasts surrounding the magma reservoir, as in Fujita et al. (2013), the calculated values represent the mean fields of peripheral domains. The magnitudes of the elastostatic effects, around $1 \mathrm{MPa}$ at most, are not negligible beneath Mt. Fuji because the differential stress there may be relatively small. For instance, Araragi et al. (2015) proposed that the maximum horizontal stress is only $1.02 \times$ greater than lithostatic pressure. They raised an example of a lithostatic pressure of $51.9 \mathrm{MPa}$ at a depth of $2.0 \mathrm{~km}$, which means the difference between the maximum horizontal stress and the lithostatic pressure would be about $1 \mathrm{MPa}$ at that depth.

A previous study of volcano-earthquake interactions (Walter and Amelung 2007) proposed that dilation of a magma reservoir initiates magma ascent, on the basis of volcano eruption data after $M \geq 9$ megathrust earthquakes worldwide. That is, earthquake-induced 
(a) Hoei

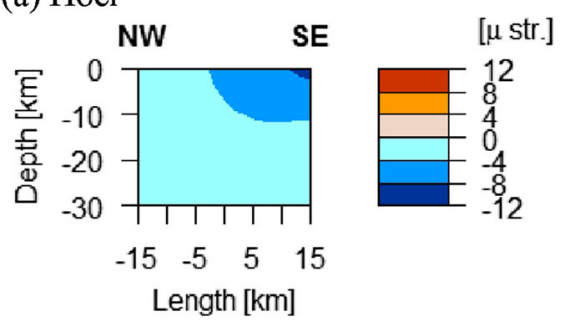

(c) Tohoku
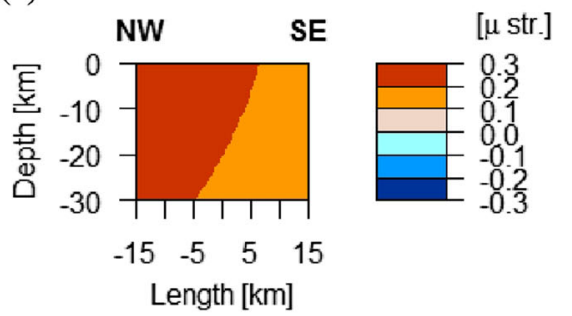

(e) Tokai

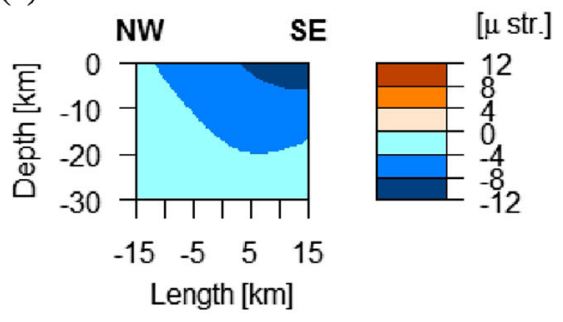

(b) Kanto

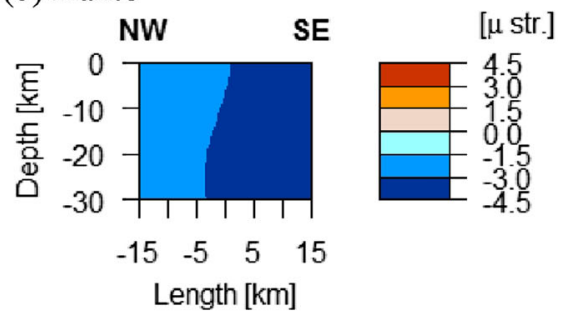

(d) ISTL
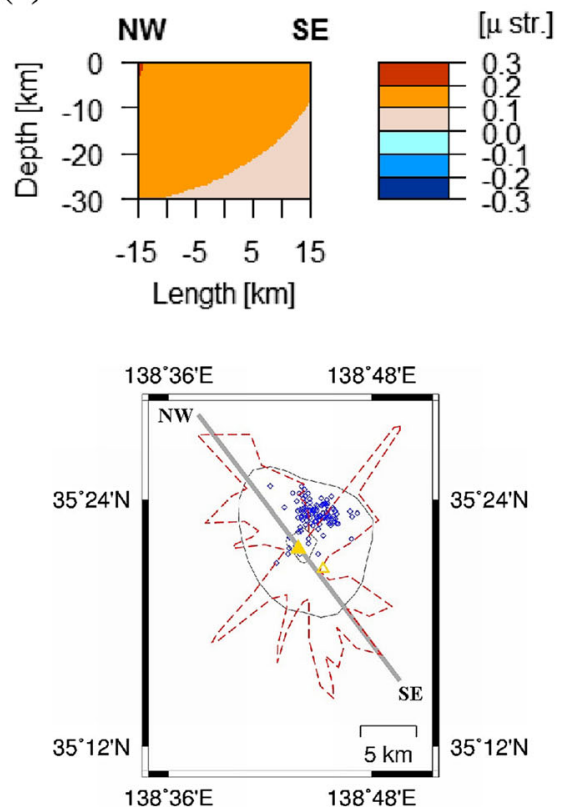

Fig. 5 Volumetric strain changes due to earthquakes in a vertical cross-section along the extended dike plane. In parts a-e, the color contours show the calculation results of volumetric strain changes from each of the five earthquake scenarios in Fig. 3 along the extended dike plane. Positive values (brown colors) indicate dilation, and negative values (blue colors) indicate compression. Horizontal axes represent horizontal distance from the summit. In the lower right subfigure, the location of the extended dike plane is shown by a thick gray line (see also Fig. 2). The southernmost point of the extended dike plane is $138^{\circ} 49.68^{\prime} \mathrm{E}, 35^{\circ} 15.18^{\prime} \mathrm{N}$; the strike is $\mathrm{N} 323^{\circ} \mathrm{E}$; and the length is $30 \mathrm{~km}$

dilation (depressurization) released dissolved volatile gases $\left(\mathrm{CO}_{2}\right.$ and $\left.\mathrm{H}_{2} \mathrm{O}\right)$, leading to volumetric expansion of a magma reservoir. This process decreases the density and viscosity of the magma, though the latter is perhaps not necessarily as suggested by Bottinga and Weill (1972) and Urbain et al. (1982). This, in turn, drives the ascent of gas bubbles with magma, causing further depressurization. In one possible scenario, this leads to an eruption through a positive feedback loop (Walter and Amelung 2007). Since the process of bubble nucleation under sudden depressurization depends on many factors (e.g., Toramaru 2014), the threshold level and conditions for the beginning of this magma ascent process remain unclear.

From this viewpoint and Fig. 5, only two earthquakes, the Tohoku earthquake (c) and the ISTL earthquake (d), have the potential to have initiated volcanic activity. At present, we know that the 2011 Tohoku earthquake has not yet triggered an eruption at Mt. Fuji. The reason for this is probably that the amount of magma dilation was small $(<1 \mu$ strain) relative to known cases of volcanic eruptions after $M \geq 9$ megathrust earthquakes (Walter and Amelung 2007) or that the magma state was not favorable to drive the ascent for eruption (Fujita et al. 2013). Although the 2011 Tohoku earthquake did not trigger an eruption at Mt. Fuji, one point to be noted is that many earthquakes, including a Mw 5.9 earthquake near Mt. Fuji, followed the 2011 Tohoku earthquake (Enescu et al. 2012; Kumazawa and Ogata 2013). We will statistically analyze these induced earthquakes in a later section. The ISTL earthquake, which occurred in 762 or 841, also did not trigger an eruption at Mt. Fuji; similarly, this is thought to be due to the small amount of magma dilation.

In contrast, Nostro et al. (1998) proposed another hypothesis linking volcanic eruptions with earthquakes 
(a) Hoei

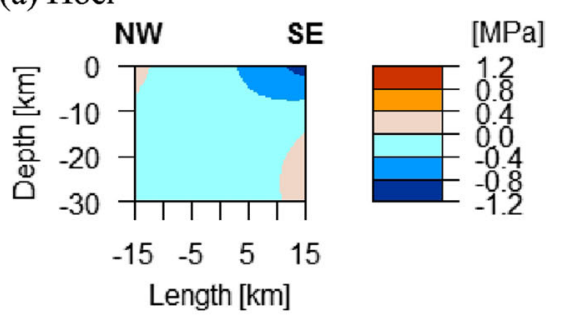

(c) Tohoku
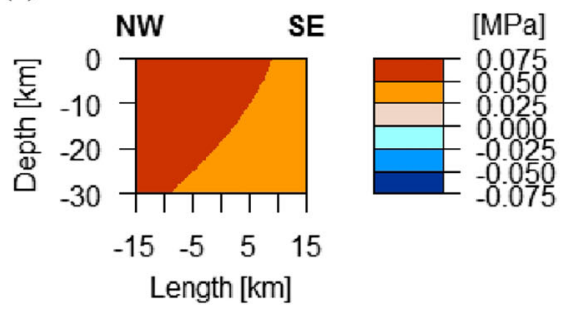

(e) Tokai

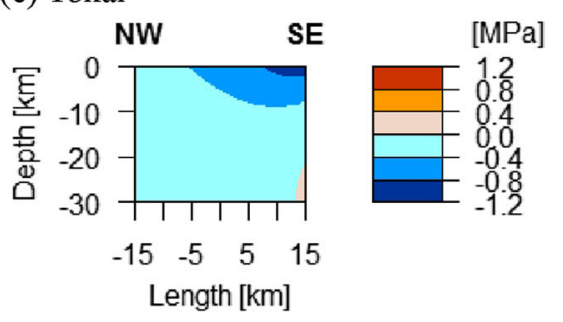

(b) Kanto

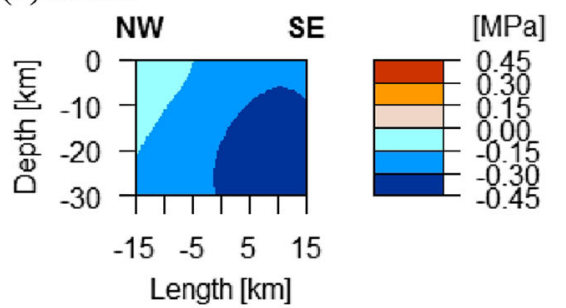

(d) ISTL
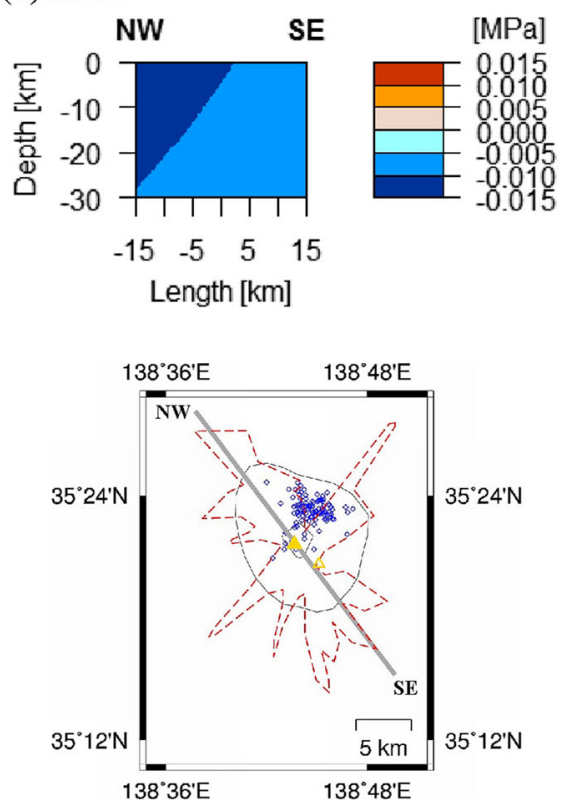

Fig. 6 Earthquake-induced changes in normal stress perpendicular to the extended dike plane. In parts a-e, the color contours show calculations of normal stress changes in each of the five earthquake scenarios in Fig. 3 along the extended dike plane. Positive values (brown colors) indicate unclamping, and negative values (blue colors) indicate clamping. Horizontal axes measure horizontal distance from the summit. In the lower right subfigure, the location of the extended dike plane is shown by a thick gray line (see also Fig. 2)

at Mt. Vesuvius. They suggested that compression of a magma reservoir and unclamping of a dike (magma pathway) by earthquakes led to eruptions. From Figs. 5 and 6, we found no cases corresponding to this model for Mt. Fuji, but the Hoei earthquake (a) was the closest analog. The 1707 Hoei earthquake compressed the basaltic magma reservoir and partly unclamped the main dike, especially in deeper regions, which might have uplifted sufficient basaltic magma to trigger magma mixing and the Plinian eruption 49 days after the Hoei earthquake (Chesley et al. 2012). The case of the 1854 Tokai earthquake (e) is a similar situation, but unclamping in the deep region of the main dike is almost negligible. This might explain why the 1854 Tokai earthquake did not trigger an eruption at Mt. Fuji. In addition, a recharge time of only $\sim 150$ years might be too short, particularly for another Plinian eruption. It is possible that the 1703 Kanto earthquake (b) did not lead to an eruption of Mt.
Fuji because of total clamping of the extended dike plane, which tends to suppress magma ascent.

Note that compression of the magma reservoir itself would not be enough to trigger an eruption. In three cases of compressional strain changes around the magma reservoir (Figs. 4a, b, e), the amounts of strain changes are $\sim-3 \times 10^{-6}$. When we assume simple spheres for the geometry of the magma reservoir, with radii of 1 and $5 \mathrm{~km}$, the volume changes of the magma reservoir are $\sim-1.3 \times 10^{4}$ and $-1.6 \times 10^{6} \mathrm{~m}^{3}$, respectively. These values are similar to those obtained by Rikitake and Sato (1989), who proposed a model of volcanic eruptions triggered by magma reservoir compression due to earthquakes (Nakamura 1971). For instance, using the above estimates of the volume changes of the magma reservoir and cross-sectional area of a vent $(S)$, we can estimate the degree of magma head ascent within the vent: we obtain a value of about 
$2.6 \times 10^{6} \mathrm{~m}^{2}$ using the following scaling relation (McNutt and Nishimura 2008):

$$
S=10^{((0.46 * \mathrm{VEI}+0.08)-0.52) / 0.29}
$$

where the VEI of the 1707 Hoei eruption was 5. Separately, if we assume an ejecta volume $(V)$ of about $1 \mathrm{~km}^{3}$ for the Hoei eruption, a scaling law between crater diameter $(D)$ and ejecta volume (Sato and Taniguchi 1997)

$$
D=0.11 V^{0.42}
$$

results in a crater diameter of $D \sim 6.6 \times 10^{2} \mathrm{~m}$ and a cross-sectional area of $S \sim 1.4 \times 10^{6} \mathrm{~m}^{2}$ (approximated as a circle). On the basis of the above results, we estimate the ascent of the magma head within the vent to be on the order of $10^{-2}-10^{0} \mathrm{~m}$. These small values seem insufficient to trigger an eruption unless additional effects occur, such as magma mixing.

In addition, the effects of dynamic stress changes, which we do not examine in this study, may promote eruption triggering (Manga and Brodsky 2006). We acknowledge that elastodynamic effects alone could explain eruptions following distant large earthquakes many hundreds of kilometers away, but there is no evidence of elastodynamic effects exceeding the elastostatic effects due to nearby earthquakes. As an example, Ichihara and Brodsky (2006) revealed that rectified diffusion, one of the popular physical mechanisms of elastodynamic effects, causes pressure changes of at most $2 \times 10^{-9}$ of initial values for seismic waves with typical amplitudes. If this is true, then elastodynamic effects due to rectified diffusion are negligible compared with the elastostatic effects reported in this study. Moreover, it seems difficult to explain the rarity of the 1707 Hoei case in terms of elastodynamic effects compared with elastostatic effects. In Fig. 11 and below, we further discuss volcano responses to earthquake deformation.

\section{Statistical analysis of seismicity after the 2011 Tohoku earthquake}

The 2011 Tohoku earthquake has not yet triggered an eruption at Mt. Fuji, but seismicity levels beneath Mt. Fuji have increased since the event (Enescu et al. 2012; Kumazawa and Ogata 2013). A recent geophysical study (Fujita et al. 2013) modeled an Mw 5.9 earthquake beneath Mt. Fuji on March 15, 2011 as occurring on a strike-slip fault. This event followed the 2011 Tohoku earthquake by 4 days, and many aftershocks occurred. We show earthquakes near Mt. Fuji after the 2011 Tohoku earthquake in Fig. 7. Those post-Tohoku earthquakes and (magmatic) low-frequency earthquakes in 2000-2014 seem to align nearly north-south, i.e., in a different direction to the extended dike plane described in previous sections. Figure 8 illustrates the hypocentral

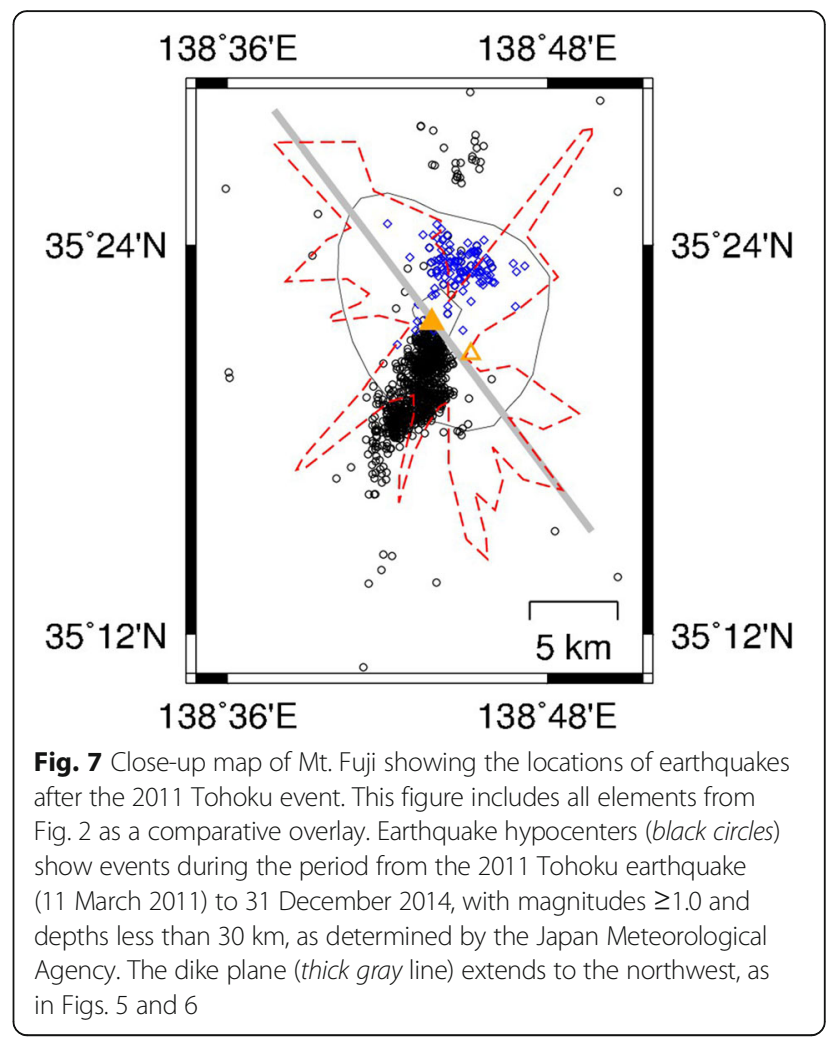

depths of post-Tohoku and low-frequency earthquakes. The depths of the former tend to be slightly shallower than those of the latter.

Whether or not post-Tohoku seismicity reflects magma movement at depth is scientifically interesting.

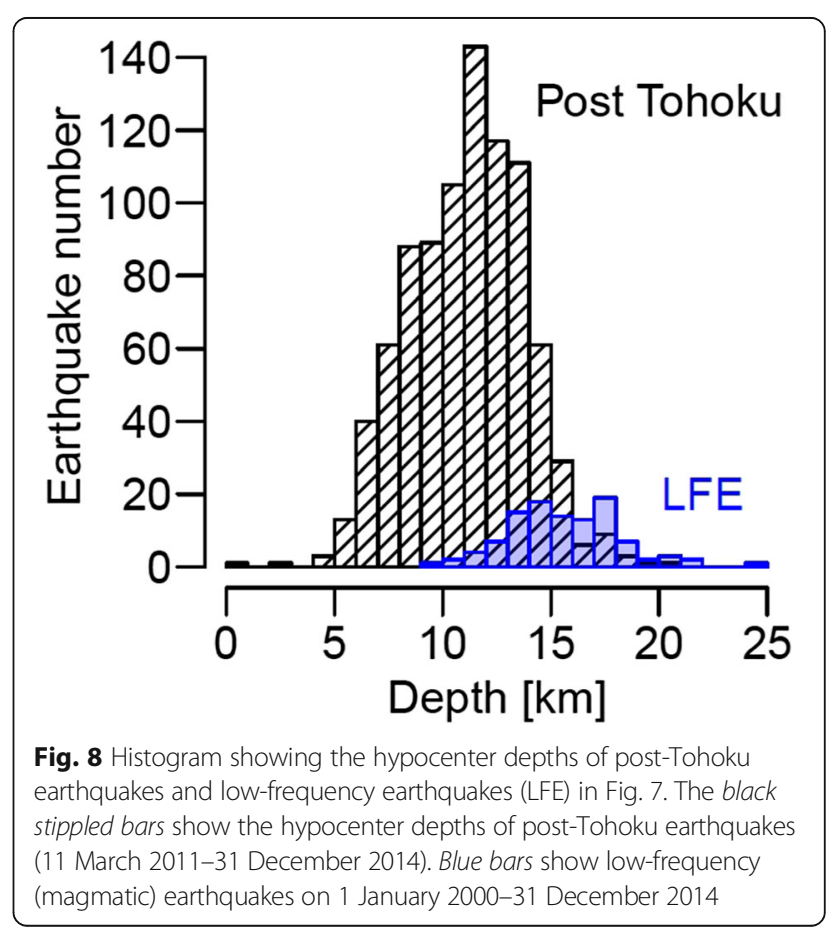


Here, we statistically analyze seismicity in 2011 for the region shown in Fig. 7 using the ETAS (epidemic-type aftershock sequence) model (Ogata 1988). Adopting an ETAS model allows us to evaluate the background seismicity rate $\mu$ without the effects of aftershocks. A seismological study by Llenos et al. (2009) proposed that changes in $\mu$ reflect alterations to aseismic stressing rates around earthquake hypocenters. We now apply this concept to seismicity around Mt. Fuji.

The ETAS model is briefly summarized as follows. (1) Every earthquake causes its own aftershocks, obeying the modified Omori law (Omori 1894; Utsu 1961) for temporal decay. (2) Aftershock productivity shows an exponential relationship with earthquake magnitude. (3) Seismicity rate at time $t$ is the sum of prior aftershock sequences and background seismicity rate. Thus, the seismicity rate $\lambda(t)$ is given by

$$
\frac{\lambda(t)=\mu+\sum_{t_{i} \leq t} K e^{\alpha\left(M_{i}-M_{c}\right)}}{\left(t-t_{i}+c\right)^{p}}
$$

where $\mu$ is the background seismicity rate, $M_{i}$ is the magnitude of the $i$ th earthquake, $M_{c}$ is the minimum earthquake magnitude, and the other parameters $(K, c, \alpha, p)$ are constants.

To estimate the model parameters, we use SASeis2006 (Ogata 2006), which estimates the five ETAS parameters $(\mu, K, c, \alpha, p)$ by minimizing the value of the Akaike Information Criterion (Akaike 1974) with a fast likelihood algorithm (Ogata et al. 1993). For the actual parameter estimation, we set $M_{c}=1.0$ to remove small earthquakes from calculation of the Gutenberg-Richter law (Gutenberg and Richter 1944) for seismic data in this region. We also assume initial parameter values for the estimation algorithm of $(\mu, K, c, \alpha, p)=(1,1,0.5,1,1.5)$.

Figure 9 shows the temporal evolution of the background seismicity rate $\mu$ in 2011. The value of $\mu$ from the Tohoku earthquake (11 March 2011) until the next month ( 30 April 2011) is one order of magnitude larger than that of the other periods. This fact suggests notable aseismic stressing around the earthquake hypocenters, since the background seismicity rate $\mu$ reflects an aseismic stress rate, possibly controlled by rate- and statedependent friction (Dieterich 1994), as proposed by Llenos et al. (2009). This aseismic stressing and the hypocenter depths (slightly shallower than for low-frequency earthquakes) might reflect magma activity above the reservoir. The nearly north-south alignment, indicated from the hypocenters of post-Tohoku seismicity and lowfrequency earthquakes (Fig. 7), suggests that magma ascended slightly along a weak zone, namely the source regions of the post-Tohoku earthquakes, including a $\mathrm{Mw}$ 5.9 fault and low-frequency earthquakes, similar to

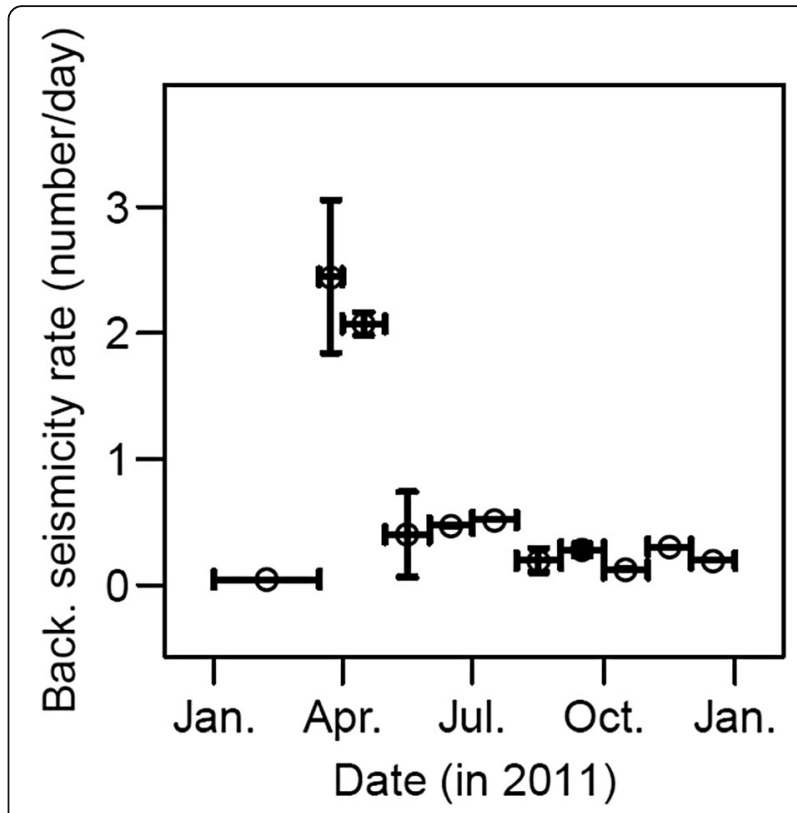

Fig. 9 Temporal evolution of the background seismicity rate $\mu$ for earthquakes in 2011 in the region shown in Fig. 7. Horizontal bars represent the estimation period, and vertical bars represent error ranges, calculated as the difference between results obtained using a precursory period (from the beginning of 2011) to the target period, and results obtained without using a precursory period. Note that the 2011 Tohoku earthquake (Mw 9) occurred on 11 March 2011, and the largest-magnitude local earthquake $(M w ~ 6)$ in this region occurred 4 days later. For reference, the background seismicity rate $\mu$ in 2010 and 2012 was 0.03 and 0.09, respectively. The cutoff magnitude used to estimate $\mu$ is 1.0 .

transform-parallel dikes (Gudmundsson 2007). Although it is unclear when the weak zone began to form, this could be a representative magma pathway for past or future activity. Herein, we call it "PPP" (possible pathway plane), similar to the dike plane.

Figure 10 illustrates the normal stress changes perpendicular to the PPP due to the five earthquakes in Fig. 3. For the cases of magma reservoir compression in Fig. $5 \mathrm{a}, \mathrm{b}, \mathrm{e}$, the PPP is totally clamped and so may not favor the triggering of an eruption (see the previous section). The stress change for the ISTL earthquake (d) has a unique pattern, with unclamping in the northern region and clamping in the southern part. In case (c) (i.e., the 2011 Tohoku earthquake and corresponding magma reservoir dilation), the PPP is totally clamped in a way that differs from the (extended) dike plane. It is probable that dilation of the magma reservoir had a weak positive effect on the ascent process of gas bubbles, but clamping restrained the bubble ascent, which then increased the stress in the area that produced the local earthquakes. The fact that the corresponding Mw 5.9 earthquake was a strike-slip earthquake (Fujita et al. 2013) is not 
(a) Hoei

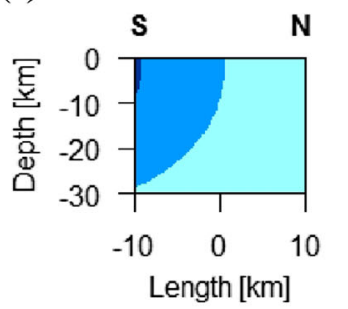

(c) Tohoku

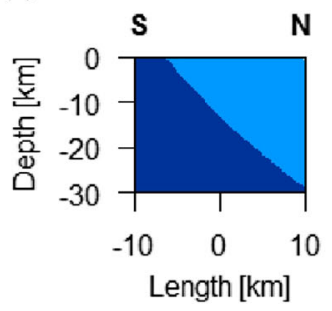

(e) Tokai

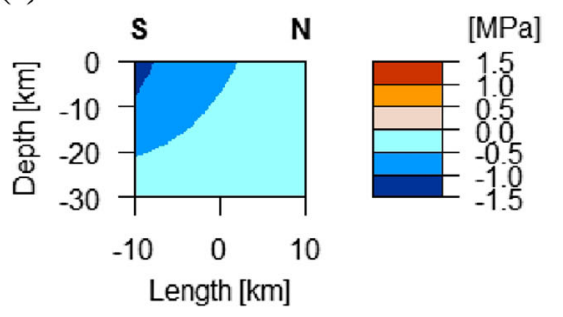

(b) Kanto

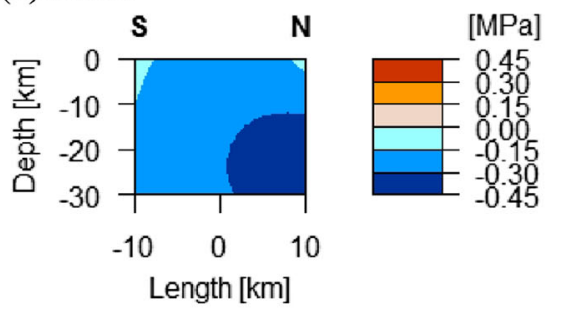

(d) ISTL
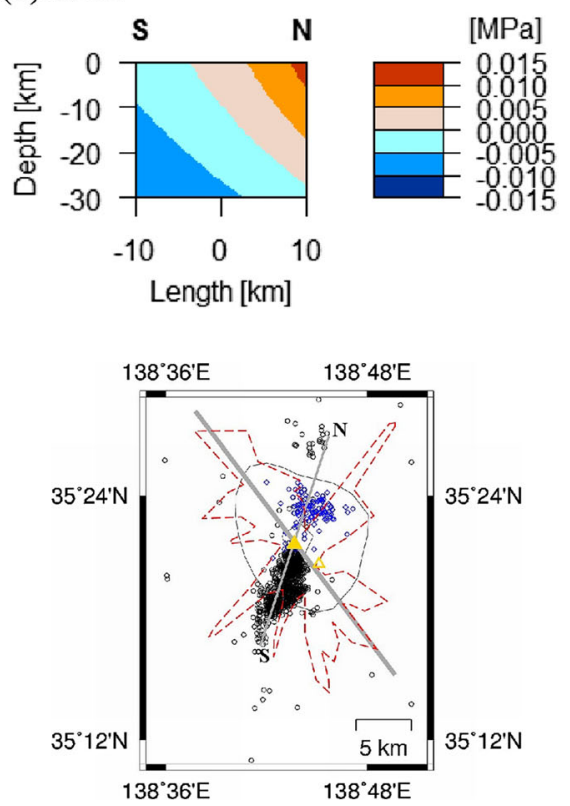

Fig. 10 Normal stress changes due to earthquakes perpendicular to the possible pathway plane (PPP). In a-e, the color contours show calculated results for each of the five earthquake scenarios in Fig. 3 along the PPP (thin gray line). As in Fig. 6, positive values (brown colors) represent unclamping, and negative values (blue colors) correspond to clamping. The horizontal axes give the horizontal distance from the summit. In the lower right figure, the location of the PPP is indicated by a thin gray line. The northernmost point of the PPP is located at $138^{\circ} 45.72^{\prime} \mathrm{E}, 35^{\circ} 26.88^{\prime} \mathrm{N}$; the strike of the plane is $\mathrm{N} 198^{\circ} \mathrm{E}$; and the length is $20 \mathrm{~km}$

curious; for instance, a geodetic study reported diketriggered aseismic strike-slip in Tanzania (Himematsu and Furuya 2015).

Why earthquakes now occur along the PPP instead of the (extended) dike plane is an ongoing mystery. Recent geophysical observations have found no evidence for volcanic activity along the (extended) dike plane. One possible hypothesis is that the main pathway of the magma changed from the (extended) dike plane following the 1707 Hoei eruption. Since the 1707 Hoei eruption was the most explosive historic eruption of Mt. Fuji, it might have changed the internal structure and stress state around the volcanic edifice. Another hypothesis is that the path of magma ascent fluctuates on relatively short time scales, and the present pathway is not along the (extended) dike plane. This hypothesis may be supported by the star-like shape of the fissure distribution (e.g., Fig. 2), but what causes the fluctuations is truly unknown. If such fluctuations are controlled by the thermal diffusion system, then their time scales would be far longer than those discussed in this study.

\section{Implications for volcano response following earthquake- induced deformation}

Figure 11 shows the calculated results of elastostatic changes around the magma reservoir and pathways (extended dike plane and PPP). The right half of the figure corresponds to the area of the former model of volcanoearthquake interactions proposed by Walter and Amelung (2007). The case of the 2011 Tohoku earthquake and post-Tohoku seismicity along the PPP of Mt. Fuji fall into this category. The upper left quadrant of the figure corresponds to the hypothesis of Nostro et al. (1998). The case of the 1707 Hoei earthquake and the subsequent Hoei eruption in the deep part of the dike plane (leading to magma mixing) are located in this part of the figure.

In many other cases, the magma reservoir was compressed and the dike was wholly clamped (lower left 


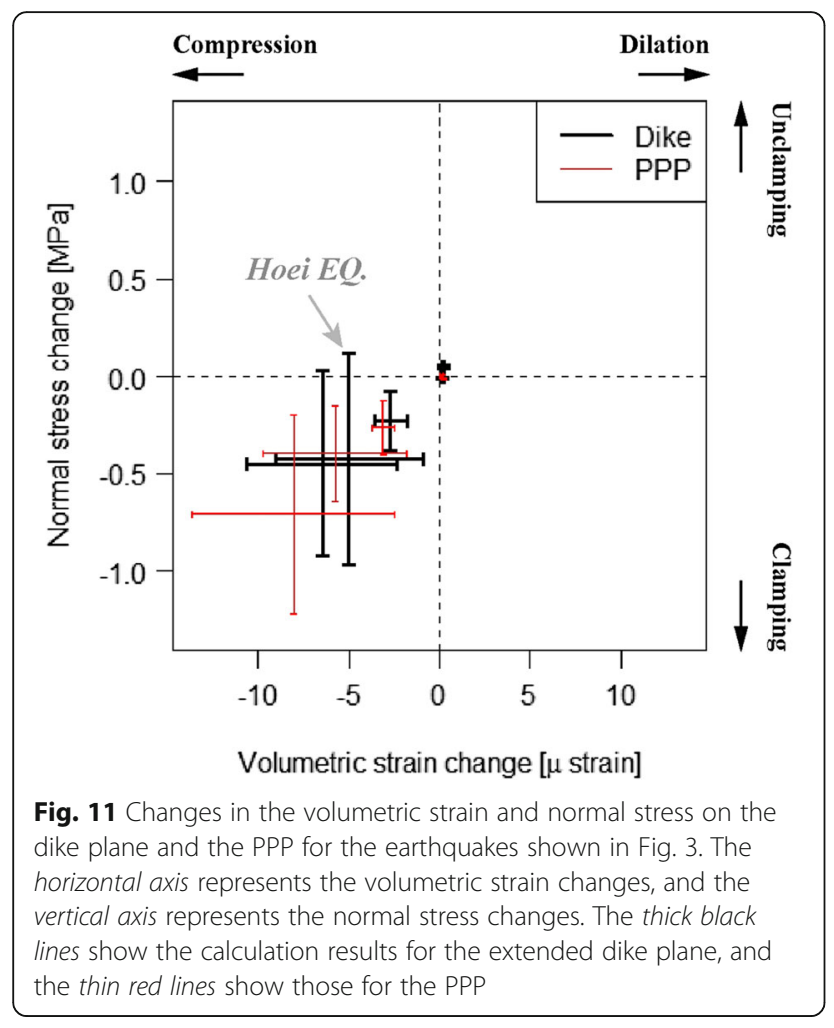

quadrant in Fig. 11). It seems that the volcanic system was not activated in these cases. This is because the compression of the magma reservoir itself would not be enough to trigger an eruption, as discussed in the previous sections. If other large earthquakes compressed the magma reservoir and unclamped the dike beneath $\mathrm{Mt}$. Fuji, the volcano system might respond acutely, as discussed previously (Nostro et al. 1998). Likewise, if another large tectonic earthquake dilated the magma reservoir by an order of magnitude more than the 2011 Tohoku earthquake and the ISTL earthquake, then the volcano system might possibly respond as proposed in a previous study (Walter and Amelung 2007). However, we cannot identify a tectonic earthquake large enough to produce such dilation. This fact implies that the magmatic system beneath Mt. Fuji is almost insulated from the elastostatic influences of large tectonic earthquakes.

\section{Effects of other possible local events near Mt. Fuji}

As a possible scenario, we examine another local earthquake near Mt. Fuji, along the Fujikawa-kako fault zone (Lin et al. 2013), that is not a large tectonic earthquake. This inland fault zone is located north of the source fault of the Ansei Tokai earthquake and possibly is a northern extension of the plate boundary (the left-hand boundary in Fig. 1). We only consider the southern segment of the fault zone (near the coast) described by a geological study (Lin et al. 2013). Hereinafter, we will refer to this as the FKFZ earthquake. We modeled the FKFZ earthquake as a west-dipping pure reverse fault with a dip angle of $30^{\circ}$ and a strike of $\mathrm{N} 180^{\circ} \mathrm{E}$. The length and width of the fault are each $15 \mathrm{~km}$, and the slip amount is $5 \mathrm{~m}$. The location of the northern corner of the upper edge is $138.6^{\circ} \mathrm{E}, 35.25^{\circ} \mathrm{N}$, and the depth is $1 \mathrm{~km}$. The moment magnitude of this local earthquake is 7.0, with

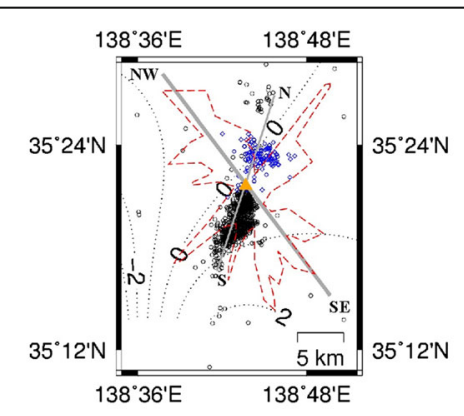

(a) Dike

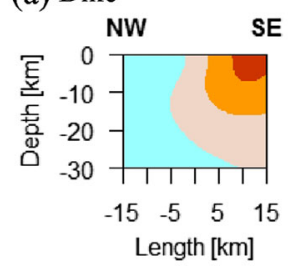

(b) PPP

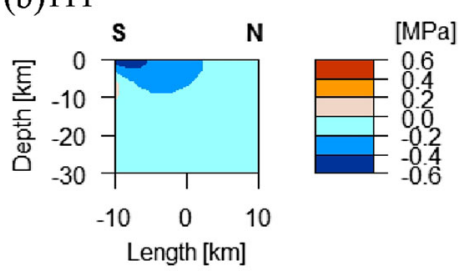

Fig. 12 Volumetric strain changes and normal stress changes perpendicular to dikes due to an Fujikawa-kako fault zone (FKFZ) earthquake. The upper figure shows isograms of volumetric strain changes at a depth of $20 \mathrm{~km}$, as in Fig. 4, with the epicenters of low-frequency earthquakes (blue squares) and post-Tohoku seismicity (black circles) superimposed. $\mathbf{a}, \mathbf{b}$ The lower figures illustrate the normal stress changes perpendicular to the extended dike plane (thick gray line in the upper figure), as in Fig. 6, and perpendicular to the PPP (thin gray line in the upper figure), as in Fig. 10 
an assumed rigidity of $30 \mathrm{GPa}$. Figure 12 shows the calculation results.

Around the northern parts of the magma pathways (both the extended dike plane and PPP), the magma reservoir is compressed and the pathways are clamped, similar to the effects of the 1703 Kanto earthquake on the extended dike plane. As discussed in the previous section, this does not favor eruption triggering. In contrast, the calculation results for the southern parts of the magma pathways (both the extended dike plane and PPP) are qualitatively similar to the case of the Tohoku earthquake. Namely, the magma reservoir is dilated while the extended dike plane is unclamped and the PPP is clamped. We note that the values of the elastostatic effects are somewhat larger than the case of the 2011 Tohoku earthquake. This local FKFZ earthquake may have the power to trigger an eruption around the southern parts of the magma pathways, following the model of Walter and Amelung (2007).

Another possible seismic event that could affect Mt. Fuji is one or more M7 slow slip events downdip of the source fault of the Tokai earthquake (Ozawa et al. 2016). Since the location of the slow slip events is near the Tokai earthquake, the effects would be qualitatively similar to, but orders of magnitude smaller than, the Tokai earthquake (case (e) in the previous sections).

\section{Conclusions}

We estimated the elastostatic effects caused by large historic and recent earthquakes in Japan around the magma reservoir of Mt. Fuji, including two possible magma pathways: a northwest-southeast-trending extended dike plane and a north-south aligned possible pathway plane. The 2011 Tohoku earthquake induced dilation of the magma reservoir, but the small amount $(<1 \mu$ strain $)$ would limit the potential for triggering eruption (Walter and Amelung 2007). The 1707 Hoei eruption (the most explosive historic eruption at Mt. Fuji), which followed the Hoei earthquake by 49 days, may be a special case that is consistent with the model of Nostro et al. (1998), i.e., triggering due to magma ascent in the deep region of the dike plane (Chesley et al. 2012). Many earthquake scenarios are characterized by compression of the magma reservoir and clamping of the magma pathway, which is far from the conditions proposed by Walter and Amelung (2007) and Nostro et al. (1998) for eruptions triggered by earthquakes. Given its location relative to mature faults in Japan, Mt. Fuji may be less susceptible to the elastostatic effects of tectonic large earthquakes. We also showed that a possible local earthquake in the Fujikawa-kako fault zone can cause far greater dilation of the magma reservoir than the 2011 Tohoku earthquake beneath the southern flank of Mt. Fuji.
Abbreviations

Mt.: Mount

\section{Acknowledgements}

We used the Generic Mapping Tools software package (Wessel and Smith 1995) to draw the maps in Figs. 1, 2, 3, 4, 5, 6, 7, 10, and 12. We thank two anonymous reviewers for comments that substantially improved the manuscript.

\section{Funding}

Not applicable.

\section{Authors' contributions}

$\mathrm{MH}$ proposed the initial idea and performed the elastostatic simulations. YM discussed the results and wrote the paper. HI discussed the results. JK performed the statistical analysis. All authors read and approved the final manuscript.

\section{Competing interests}

The authors declare that they have no competing interests.

Received: 4 May 2016 Accepted: 13 October 2016

Published online: 24 October 2016

\section{References}

Akaike H (1974) A new look at the statistical model identification. IEEE Trans Autom Contr 19:716-723. doi:10.1109/TAC.1974.1100705

Ando M (1975) Source mechanisms and tectonic significance of historical earthquakes along the Nankai Trough, Japan. Tectonophysics 27:119-140. doi:10.1016/0040-1951(75)90102-X

Araragi KR, Savage MK, Ohminato T, Aoki Y (2015) Seismic anisotropy of the upper crust around Mount Fuji, Japan. J Geophys Res 120:2739-2751. doi:10.1002/2014JB011554

Bonali FL, Tibaldi A, Corazzato C et al (2013) Quantifying the effect of large earthquakes in promoting eruptions due to stress changes on magma pathway: the Chile case. Tectonophysics 583:54-67. doi:10.1016/j.tecto.2012. 10.025

Bottinga Y, Weill DF (1972) The viscosity of magmatic silicate liquids; a model calculation. American J Sci 272:438-475. doi:10.2475/ajs.272.5.438

Chesley C, LaFemina PC, Puskas C, Kobayashi D (2012) The 1707 Mw 8.7 Hoei earthquake triggered the largest historical eruption of Mt. Fuji. Geophys Res Lett 39:L24309. doi:10.1029/2012GL053868

Dieterich J (1994) A constitutive law for rate of earthquake production and its application to earthquake clustering. J Geophys Res 99:2601-2618. doi:10. 1029/93JB02581

Eichelberger JC (1980) Vesiculation of mafic magma during replenishment of silicic magma reservoirs. Nature 288:446-450. doi:10.1038/288446a0

Enescu B, Aoi S, Toda S et al (2012) Stress perturbations and seismic response associated with the 2011 M9.0 Tohoku-oki earthquake in and around the Tokai seismic gap, central Japan. Geophys Res Lett 39:L00G28. doi:10.1029/2012GL051839

Fujita E, Kozono T, Ueda H et al (2013) Stress field change around the Mount Fuji volcano magma system caused by the Tohoku megathrust earthquake, Japan. Bull Vol 75:1-14. doi:10.1007/s00445-012-0679-9

Gudmundsson A (2007) Infrastructure and evolution of ocean-ridge discontinuities in Iceland. J Geodynamics Vol 43:6-29. doi:10.1016/j.jog.2006. 09.002

Gutenberg B, Richter CF (1944) Frequency of earthquakes in California. Bull Seis Soc Am 34:185-188

Himematsu Y, Furuya M (2015) Aseismic strike-slip associated with the 2007 dike intrusion episode in Tanzania. Tectonophysics 656:52-60. doi:10.1016/j.tecto. 2015.06 .005

Ichihara M, Brodsky E (2006) A limit on the effect of rectified diffusion in volcanic systems. Geophys Res Lett 33:L02316. doi:10.1029/2005GL024753

Ida Y (2009) Dependence of volcanic systems on tectonic stress conditions as revealed by features of volcanoes near Izu peninsula, Japan. J Vol Geotherm Res 181:35-46. doi:10.1016/j.jvolgeores.2008.12.006

Ishibashi K (2004) Status of historical seismology in Japan. Ann Geophys 47:339-368

Ishibashi K (1977) Re-examination of a great earthquake expected in the Tokai district, central Japan-possibility of the "Suruga Bay earthquake". Rep Coord Comm Earthq Predict 17:126-132 
Kinoshita SM, Igarashi T, Aoki Y, Takeo M (2015) Imaging crust and upper mantle beneath Mount Fuji, Japan, by receiver functions. J Geophys Res 120:3240-3254. doi:10.1002/2014JB011522

Kondo H, Toda S, Okumura K et al (2008) A fault scarp in an urban area identified by LiDAR survey: a case study on the Itoigawa-Shizuoka Tectonic Line, central Japan. Geomorphology 101:731-739. doi:10.1016/j.geomorph.2008.02.012

Koyama M (1998) Reevaluation of the eruptive history of Fuji Volcano, Japan, mainly based on historical documents (in Japanese with English abstract). Bull Volcanol Soc Jpn 43:323-347

Kumazawa T, Ogata Y (2013) Quantitative description of induced seismic activity before and after the 2011 Tohoku-Oki earthquake by nonstationary ETAS models. J Geophys Res 118:1-18. doi:10.1002/2013JB010259

Lemarchand N, Grasso J-R (2007) Interactions between earthquakes and volcano activity. Geophys Res Lett 34:L24303. doi:10.1029/2007GL031438

Lin A, lida K, Tanaka H (2013) On-land active thrust faults of the Nankai-Suruga subduction zone: the Fujikawa-kako Fault Zone, central Japan. Tectonophysics 601:1-19. doi:10.1016/j.tecto.2013.04.020

Linde AT, Sacks IS (1998) Triggering of volcanic eruptions. Nature 395:888-890. doi:10.1038/27650

Llenos AL, McGuire JJ, Ogata Y (2009) Modeling seismic swarms triggered by aseismic transients. Earth Planet Sci Lett 281:59-69. doi:10.1016/j.epsl. 2009.02.011

Manga M, Brodsky E (2006) Seismic triggering of eruptions in the far field: volcanoes and geysers. Ann Rev Earth Planet Sci 34:263-291. doi:10.1146/annurev.earth.34.031405.125125

McNutt SR, Nishimura T (2008) Volcanic tremor during eruptions: temporal characteristics, scaling and constraints on conduit size and processes. J Vol Geotherm Res 178:10-18

Miyaji N (1988) History of younger Fuji Volcano (in Japanese with English abstract). J Geol Soc Japan 94:433-452

Nakamichi H, Ukawa M, Sakai S (2004) Precise hypocenter locations of midcrustal low-frequency earthquakes beneath Mt. Fuji, Japan. Earth Planets Sp 56:e37-e40. doi:10.1186/BF03352542

Nakamichi H, Watanabe H, Ohminato T (2007) Three-dimensional velocity structures of Mount Fuji and the South Fossa Magna, central Japan. J Geophys Res. doi: 10.1029/2005JB004161

Nakamura K (1977) Volcanoes as possible indicators of tectonic stress orientation-principle and proposal. J Vol Geotherm Res 2:1-16. doi:10.1016/0377-0273(77)90012-9

Nakamura K (1975) Volcano structure and possible mechanical correlation between volcanic eruptions and earthquakes (in Japanese with English abstract). Bull Volcanol Soc Jpn 20:229-240

Nakamura K (1971) Volcano as a possible indicator of crustal strain (in Japanese with English abstract). Bull Volcanol Soc Jpn 16:63-71

Nishimura T, Munekane H, Yarai H (2011) The 2011 off the Pacific coast of Tohoku Earthquake and its aftershocks observed by GEONET. Earth Planets Sp 63:631-636. doi:10.5047/eps.2011.06.025

Nostro C, Stein RS, Cocco M et al (1998) Two-way coupling between Vesuvius eruptions and southern Apennine earthquakes, Italy, by elastic stress transfer. J Geophys Res 103:24487-24504. doi:10.1029/98JB00902

Ogata Y (1988) Statistical models for earthquake occurrences and residua analysis for point processes. J Am Stat Assoc 83:9-27

Ogata Y (2006) Statistical analysis of seismicity: updated version (SASeis 2006). In: Computer science monographs: a publication of the Institute of Statistical Mathematics; No. 33. The Institute of Statistical Mathematics, pp 1-28

Ogata Y, Matsu'ura RS, Katsura K (1993) Fast likelihood computation of epidemic type aftershock-sequence model. Geophys Res Lett 20:2143-2146. doi:10.1029/93GL02142

Okada Y (1992) Internal deformation due to shear and tensile faults in a halfspace. Bull Seis Soc Am 82:1018-1040

Okumura K (2001) Paleoseismology of the Itoigawa-Shizuoka tectonic line in central Japan. J Seismol 5:411-431. doi:10.1023/A:1011483811145

Omori F (1894) On the aftershocks of earthquakes. J Coll Sci Imp Univ Tokyo 7:111-120

Ozawa S, Tobita M, Yarai H (2016) A possible restart of an interplate slow slip adjacent to the Tokai seismic gap in Japan. Earth Planets Space 68:54. doi:10. 1186/s40623-016-0430-4

Panayotopoulos Y, Hirata N, Sato H et al (2014) Investigating the role of the Itoigawa-Shizuoka tectonic line towards the evolution of the Northern Fossa Magna rift basin. Tectonophysics 615-616:12-26. doi:10.1016/j.tecto.2013.12.014
Pollard DD, Segall P (1987) Theoretical displacements and stresses near fractures in rock: with applications to faults, joints, veins, dikes, and solution surfaces. In: Fracture Mechanics of Rock. pp 277-349

Rikitake T, Sato R (1989) Up-squeezing of magma under tectonic stress. J Phys Earth 37:303-311

Sato H, Iwasaki T, Kawasaki S et al (2004) Formation and shortening deformation of a back-arc rift basin revealed by deep seismic profiling, central Japan. Tectonophysics 388:47-58. doi:10.1016/j.tecto.2004.07.004

Sato H, Taniguchi H (1997) Relationship between crater size and ejecta volume of recent magmatic and phreato-magmatic eruptions: implications for energy partitioning. Geophys Res Lett 24:205-208. doi:10.1029/93GL02142

Seno T (2012) Great earthquakes along the Nankai Trough: a new idea for their rupture mode and time series (in Japanese with English abstract). Zisin 64:97-116

Suzuki Y, Fujii T (2010) Effect of syneruptive decompression path on shifting intensity in basaltic sub-Plinian eruption: Implication of microlites in Yufune-2 scoria from Fuji volcano, Japan. J Vol Geotherm Res 198:158-176

Takada A, Ishizuka Y, Nakano S, et al (2007) Characteristic and evolution inferred from eruptive fissures of Fuji volcano, Japan (in Japanese with English abstract). In: Aramaki S, Fujii T, Nakada S, Miyaji N (eds) Fuji Volcano. Yamanashi Institute of Environmental Sciences, pp 183-202

Toramaru A (2014) On the second nucleation of bubbles in magmas under sudden decompression. Earth Planet Sci Lett 404:190-199

Tsuya H (1955) Geological and petrological studies of volcano, Fuji, V.: 5. On the 1707 eruption of Volcano Fuji. Bull Earthquake Res Inst 64:341-383

Ukawa M (1991) Collision and fan-shaped compressional stress pattern in the Izu Block at the northern edge of the Philippine Sea Plate. J Geophys Res 96:713-728. doi:10.1029/90JB02142

Urbain G, Bottinga Y, Richet P (1982) Viscosity of liquid silica, silicates and alumino-silicates. Geochim Cosmochim Acta 46:1061-1072. doi:10.1016/00167037(82)90059-X

Utsu T (1961) A statistical study on the occurrence of aftershocks. Geophys Mag 30:521-605

Walter TR, Amelung F (2007) Volcanic eruptions following $M \geq 9$ megathrust earthquakes: implications for the Sumatra-Andaman volcanoes. Geology 35:539-542. doi:10.1130/G23429A.1

Wessel P, Smith WHF (1995) New version of the generic mapping tools released. Eos Trans AGU 76:329. doi:10.1029/95EO00198

\section{Submit your manuscript to a SpringerOpen ${ }^{\mathcal{O}}$ journal and benefit from:}

- Convenient online submission

- Rigorous peer review

- Immediate publication on acceptance

- Open access: articles freely available online

- High visibility within the field

- Retaining the copyright to your article

Submit your next manuscript at springeropen.com 